\title{
Glioblastoma entities express subtle differences in molecular composition and response to treatment
}

\author{
JOANA BALÇA-SILVA ${ }^{1-3}$, DIANA MATIAS ${ }^{3,4}$, ANÁLIA DO CARMO ${ }^{1,5}$, LUIZ GUSTAVO DUBOIS ${ }^{3}$, \\ ANA CRISTINA GONÇALVES ${ }^{1,6,7}$, HENRIQUE GIRÃO ${ }^{1,2}$, NATHALIE HENRIQUES SILVA CANEDO ${ }^{8}$, \\ ANA HELENA CORREIA ${ }^{8}$, JORGE MARCONDES DE SOUZA ${ }^{9}$, ANA BELA SARMENTO-RIBEIRO ${ }^{1,6,7}$, \\ MARIA CELESTE LOPES $S^{1,10}$ and VIVALDO MOURA-NETO ${ }^{3}$
}

\begin{abstract}
${ }^{1}$ Center for Neuroscience and Cell Biology and Institute for Biomedical Imaging and Life Sciences (CNC.IBILI), Coimbra; ${ }^{2}$ Faculty of Medicine, University of Coimbra, Coimbra, Portugal; ${ }^{3}$ Instituto Estadual do Cérebro Paulo Niemeyer (IECPN), Secretaria de Estado de Saúde, Rio de Janeiro; ${ }^{4}$ Federal University of Rio de Janeiro (UFRJ), Rio de Janeiro, Brazil; ${ }^{5}$ Clinical Pathology Department, Centro Hospitalar Universitário de Coimbra (CHUC), Coimbra; ${ }^{6}$ Laboratory of Oncobiology and Hematology and CIMAGO, Faculty of Medicine, University of Coimbra (FMUC), Coimbra; ${ }^{7}$ Hematology Department, Centro Hospitalar Universitário de Coimbra (CHUC), Coimbra, Portugal; Departments of ${ }^{8}$ Pathology and ${ }^{9}$ Neurosurgery, Clementino Fraga Filho Hospital, Federal University of Rio de Janeiro, School of Medicine, Rio de Janeiro, Brazil; ${ }^{10}$ Faculty of Pharmacy, University of Coimbra (FFUC), Coimbra, Portugal
\end{abstract}

Received January 11, 2017; Accepted June 6, 2017

DOI: 10.3892/or.2017.5799

\begin{abstract}
Glioblastoma (GBM) is a grade IV astrocytoma. GBM patients show resistance to chemotherapy such as temozolomide (TMZ), the gold standard treatment. In order to simulate the molecular mechanisms behind the different chemotherapeutic responses in GBM patients we compared the cellular heterogeneity and chemotherapeutic resistance mechanisms in different GBM cell lines. We isolated and characterized a human GBM cell line obtained from a GBM patient, named GBM11. We studied the GBM11 behaviour when treated with Tamoxifen (TMX) that, among other functions, is a protein kinase $\mathrm{C}$ ( $\mathrm{PKC}$ ) inhibitor, alone and in combination with $\mathrm{TMZ}$ in comparison with the responses of U87 and U118 human GBM cell lines. We evaluated the cell death, cell cycle arrest and cell proliferation, mainly through PKC expression, by flow cytometry and western blot analysis and, ultimately, cell migration capability and F-actin filament disorganization by fluorescence microscopy. We demonstrated that the constitutive activation of p-PKC seems to be one of the main metabolic implicated on GBM malignancy. Despite
\end{abstract}

Correspondence to: Professor Vivaldo Moura-Neto, Instituto Estadual do Cérebro Paulo Niemeyer (IECPN), Secretaria de Estado de Saúde, Rua do Rezende, 156 Centro, Rio de Janeiro, RJ 20231-092, Brazil

E-mail: vivaldomouraneto@gmail.com

Abbreviations: GBM, glioblastoma; GSCs, glioma stem-like cells; TMX, tamoxifen; TMZ, temozolomide; PGP, P-glycoprotein; PKC, protein kinase $\mathrm{C}$

Key words: glioblastoma, glioma cancer stem-like cells, cellular heterogeneity, chemotherapeutic resistance, cell motility of its higher resistance, possibly due to the overexpression of P-glycoprotein and stem-like cell markers, GBM11 cells presented a subtle different chemotherapeutic response compared to U87 and U118 cells. The GBM11, U87, U118 cell lines show subtle molecular differences, which clearly indicate the characterization of GBM heterogeneity, one of the main reasons for tumor resistance. The adding of cellular heterogeneity in molecular behaviour constitutes a step closer in the understanding of resistant molecular mechanisms in GBM, and can circumvents the eventual impaired therapy.

\section{Introduction}

Glioblastoma is the most common and malignant type of primary brain tumor $(1,2)$. The median survival of GBM patients remains $\sim 15$ months under the gold standard treatment with temozolomide (TMZ) (1,3-5). GBM chemoresistance has been linked to several mechanisms. The presence of stem-like cells, overexpression of efflux proteins such as P-glycoprotein (PGP), the methylation of MGMT promoter and the constitutive activation of proliferative signaling pathways, mainly phosphorylated protein kinase $\mathrm{C}$ (PKC), have been described as some of the main reasons of GBM chemoresistance and contribute to the increased proliferation, survival and motility of GBM cells (6-13). We previously reported that the combination of tamoxifen (TMX), a PKC inhibitor, with TMZ can reduce the amount of phosphorylated PKC-pan and contribute to the reduction of aggressive behaviour of the GBM cell lines U87 and U118 (6). In fact, a large spectrum of TMX targets other than estrogen receptors have been defined as key mediators of signal pathways activating cell proliferation, determining aggressive course of neoplastic disorders or tumor chemosensitivity, namely in GBM (14). Taking into consideration the genetic and molecular variability in GBM cell lines, 
we i) isolated and characterized a human GBM cell line, termed GBM11; and ii) compared the effect of TMX and TMZ co-treatment on this GBM cell line with that observed in U87 and U118 cell lines in our previous study (6). The treatment comparison between the GBM11 cells and the U87 and U118 cells with TMX and TMZ as chemotherapeutic compounds and their combinations could reveal distinct cytotoxic effects among GBM cells, indicating an individualized response to therapy.

GBM11 cell line was isolated as previously described from surgical biopsies from a glial tumor diagnosed as $\operatorname{GBM}(15,16)$. Next, we characterized the GBM11 considering their stem cell properties, i.e. expression of stem-like cell markers, histopathological features, analysis of GFAP and Nestin expression, properties found in the other established cell lines. We also analysed PGP expression in GBM11, U87 and U118 cell lines. We tested the sensitivity of GBM11 cells to TMZ treatment alone as the gold standard for GBM treatment. We finally evaluated the effect of TMX and TMZ co-treatment on GBM11 cells by comparing the results with U87 and U118 cell lines, previously published by our group (6). Principally, our results showed that our GBM11 cells presented a higher resistance to TMX and/or TMZ treatment compared to that obtained with U87 and U118 cells, probably due to the existence of a stem-like cell population and a higher PGP expression. In fact, the overexpression of PGP at the blood-brain-barrier (BBB) is discussed as a major mechanism of pharmacoresistance in cancer, namely in GBM (17), but some studies also suggested an intrinsic chemoresistance role of $M R P 1$ expression in GBM tumor cells, independent of the BBB endothelial transport system (18).

The aim of our present study is to introduce a new human GBM cell line, GBM11, that could serve as a patient-specific approach to understand the mechanisms underlying chemotherapeutic resistance expanding the resources available for preclinical studies in GBM treatment. We believe that the introduction of this cellular resistant model could provide a potential testing platform to investigate new therapeutic strategies. We consider that our new GBM cell line derived from human tumor cells, is able to introduce the variability of a patient-specific response to therapy in a way to reinforce the individually-designed cancer therapy approach and circumvent the eventual impaired therapy.

\section{Materials and methods}

Materials. Dulbecco's modified Eagle's medium (DMEM) and fetal bovine serum (FBS) were supplied by Invitrogen (Paisley, UK). The anti-mouse and anti-rabbit antibodies were obtained from GE Healthcare (Little Chalfont, UK). Protease and phosphatase inhibitors were supplied by Roche Diagnostics (Indianapolis, IN, USA). Antibody for PKC-pan pan was from Cell Signaling Technology (Beverly, MA, USA). Mouse anti-tubulin and mouse anti-actin antibody were obtained from Boehringer (Mannheim, Germany). Temozolomide (TMZ) and tamoxifen (TMX) were dissolved in dimethyl sulfoxide (DMSO) at a stock concentration of $0.133 \mathrm{M}$ and $3 \mathrm{mM}$, respectively, and diluted in culture medium according to the concentrations used. Both TMZ and TMX were from Sigma-Aldrich Chemicals (St. Louis, MO, USA).
3-(4,5-dimethyl-2-thiazolyl)-2,5-diphenyl-2H-tetrazolium bromide (MTT) was from Sigma-Aldrich Chemicals. Glucose was from Merck (Darmstadt, Germany). Fungizone was from Bristol-Meyers Squibb (Princeton, NJ, USA). Penicillin/ streptomycin was from Gibco (Carlsbad, CA, USA). Rabbit anti-glial fibrillary acidic protein (GFAP) and Nestin clone 10c2 and PVDF membranes were from Millipore (Billerica, MA, USA). The 5-ethynyl-2'-deoxyuridine (EdU) kit was from Invitrogen (Carlsbad, CA, USA). Annexin V and propidium iodide (PI) were from BD Biosciences (Biolegends, San Diego, CA, USA). PI/RNase was from Immunostep (Salamanca, Spain). The phalloidin and the anti-human PGP (fluorescein isothiocyanate (FITC) mouse anti-human P-glycoprotein) were from BD Biosciences. NZYDNA Ladder VI was from (NZYTech, Lisbon, Portugal). Antibodies for Nanog (\#3580), Oct-4A (\#2840) and SOX2 (\#D6D9), Slug (\#9585) were from Cell Signaling Technology (Beverly, MA, USA). Mouse antiactin antibody was from Boehringer. PVDF membranes were from Millipore; 2x Laemmli buffer and $\beta$-mercaptoethanol were obtained from Bio-Rad Laboratórios do Brasil (São Paulo, Brazil).

Cell line culture conditions. The GBM11 cell line was established and characterized in our laboratory as previously described for other cell lines $(15,16)$ using the same protocols to U87 and U118 cell cultures. Briefly, GBM11 cells were obtained by surgical biopsy from a 57-year-old male patient bearing a recurrent glioblastoma previously treated with $\mathrm{TMZ}$ concomitantly with radiotherapy, who had given written consent to the study. All procedures were in agreement with the Brazilian Ministry of Health Ethics Committee (CONEP no. 2340). The tumor cells were termed GBM11. The tumor sample was analysed histologically by the Pathology Service of the Federal University of Rio de Janeiro Hospital as previously described (16). The biopsy was washed in DMEM medium, mechanically dissociated and then plated directly plated on a 24-well plate and/or $25-\mathrm{cm}^{2}$ tissue culture flasks with DMEM supplemented with $3.5 \mathrm{mg} / \mathrm{ml}$ glucose, $0.1 \mathrm{mg} / \mathrm{ml}$ penicillin, $0.14 \mathrm{mg} / \mathrm{ml}$ streptomycin and $10 \%$ inactivated FBS. Cells were maintained at $37^{\circ} \mathrm{C}$ in an atmosphere containing $95 \%$ air and $5 \% \mathrm{CO}_{2}$. The medium was changed every 3 days until the culture was near confluence, approximately after 7 days. Then, cell cultures were fixed and processed for characterization as described in Faria et al (16). Cells were also frozen in FBS and $10 \%$ DMSO in cryotubes and conserved in liquid N2. For the experiments, unsynchronized cells were treated with different concentrations of TMX or TMZ. The curve for the calculation of each drug concentration necessary to inhibit cell proliferation by $50 \%$ was fitted using GraphPad Prism 5 for Windows (version 5.00; GraphPad Software, Inc., San Diego, CA, USA).

Cell viability evaluation by MTT assay. Metabolically active cells were assessed using the 3-(4,5-dimethylthiazol-2-yl)-2,5diphenyl tetrazolium bromide (MTT) reduction colorimetric assay, as described by Balça-Silva et al (6). Briefly, GBM11 cells were plated in 96 multi-well plates and then were incubated with TMX and/or TMZ at different concentrations for $48 \mathrm{~h}$. After $48 \mathrm{~h}$ of incubation, MTT $(5 \mathrm{mg} / \mathrm{ml})$ was added to each well at a final concentration of $0.5 \mathrm{mg} / \mathrm{ml}$ and left for $1 \mathrm{~h}$. In order to dissolve the blue formazan crystals, $200 \mu \mathrm{l}$ of DMSO 
was added. GBM11 cells were maintained in fresh medium at $37^{\circ} \mathrm{C}$ in an atmosphere of $95 \%$ humidity and $5 \% \mathrm{CO}_{2}$ for $48 \mathrm{~h}$. The absorbance was read in a microplate reader at $570 \mathrm{~nm}$. Cytotoxicity was evaluated as the percentage of metabolically active in relation to untreated cells. The drug concentration required to reduce the percentage of metabolically active cells by $50 \%\left(\mathrm{IC}_{50}\right)$ was estimated with GraphPad.

Histological analysis and immunofluorescence. Haematoxylin was used to stain and counterstain paraffin tumor sections for histopathological analysis. Sections were mounted with Permount $^{\mathrm{TM}}$. For immunofluorescence analysis, $10 \times 10^{4}$ cells $/ \mathrm{ml}$ were plated on 24-well plates, as described by Khan et al (15). Briefly, cells were fixed with 4\% PFA in phosphate-buffered saline (PBS) for $15 \mathrm{~min}$ and then washed with PBS and incubated with $5 \%$ BSA/PBS for 30 min. Cells were incubated with mouse anti-Nestin (1:200), rabbit anti-GFAP (1:500). Cells were incubated overnight at $4^{\circ} \mathrm{C}$ with the primary antibodies and then washed with PBS and incubated with secondary antibodies conjugated with Alexa Fluor 488 (goat anti-mouse; 1:250), Alexa Fluor 488 (goat anti-rabbit; 1:250) overnight. The day after, cells were washed with PBS, stained with DAPI, then washed with PBS again and mounted. Negative controls were performed with non-immune rabbit or mouse IgG. Cells were imaged using a DMi8 advanced fluorescence microscope (Leica Microsystems, Wetzlar, Germany) and analysed with the aid of Leica LAS AF Lite, at 63x magnification. Imaging processing was performed sing the software ImageJ $1.49 \mathrm{v}$.

Analysis of F-actin filament organization. GBM11 cells were incubated with TMZ and/or TMX for $48 \mathrm{~h}$ and F-actin filament organization was studied using Alexa Fluor 568 phalloidin staining solution $(5 \mathrm{U} / \mathrm{ml})$ as previously described (6). Briefly, cells were fixed with $2.5 \%$ paraformaldehyde/PBS for $20 \mathrm{~min}$. Next, cells were permeabilized with $0.1 \%$ Triton X-100/PBS for $3 \mathrm{~min}$ and then incubated for $30 \mathrm{~min}$ with the Alexa Fluor 568 phalloidin staining solution $(5 \mathrm{U} / \mathrm{ml})$ in PBS containing $1 \%$ BSA. Nuclei were stained with DAPI for $2 \mathrm{~min}$. Finally, the coverslips were mounted on glass slides and inspected under a Zeiss LSM 510 Meta confocal microscope at a magnification of x40, using a filter set with an excitation filter of $568 \mathrm{~nm}$ and a barrier filter of $585 \mathrm{~nm}$. Then, cells were viewed on a Zeiss LSM image browser (Version 4.2.0.121; Carl Zeiss, Inc., Oberkochen, Germany).

PGP expression by flow cytometry. The expression of PGP in the different GBM cell lines U87, U118 and GBM11 was assessed by flow cytometry using monoclonal antibodies labelled with fluorochromes. For each assay, $10^{6}$ cells were used and data on at least 10,000 events were collected using a FACSCalibur flow cytometer, CellQuest software (Becton-Dickinson, Franklin Lakes, NJ, USA), and analysed using CellQuest ${ }^{\mathrm{TM}}$ software (Becton-Dickinson). Since PGP is a membrane protein, cells were centrifuged at $300 \mathrm{x} \mathrm{g}$ and incubated for $15 \mathrm{~min}$ at room temperature with the monoclonal antibodies: anti-human PGP [fluorescein isothiocyanate (FITC) and mouse anti-human P-glycoprotein (BD Biosciences)].

MGMT methylation pattern analysis. DNA from GBM cell lines U87, U118 and GBM11 was extracted according to the standard procedures. One microgram of genomic DNA was treated with sodium bisulfite using the EpiTect Bisulfite kit (Qiagen, Hilden, Germany). Methylation-specific PCRs of MGMT gene promoters were carried out as described by Gonçalves et al (19) by the EpiTect PCR control DNA kit (Qiagen) according to the manufacturer's instructions. PCR products were resolved on $4 \%$ agarose gels, stained with ethidium bromide and observed under UV illumination.

Western blot analysis. PKC-pan expression was analysed by western blot analysis as described by Balça-Silva et al (6). Also, the expression of SOX2, Oct-4A and NANOG were analysed by western blot analysis as originally described by Towbin et al (20) and adapted by Balça-Silva et al (6) and Kahn et al (15) in both the GBM and GBM-SF cell lines. Briefly, cells were centrifuged at $500 \mathrm{x}$ g for $10 \mathrm{~min}$ at $4^{\circ} \mathrm{C}$. The supernatants were discarded. Cells were then resuspended in RIPA buffer (50 mM Tris- $\mathrm{HCl}$ at $\mathrm{pH} 8.0,150 \mathrm{mM} \mathrm{NaCl}$, $1.0 \%$ NP-40, $0.5 \%$ sodium deoxycholate, $0.1 \%$ SDS and $2 \mathrm{mM}$ EDTA, supplemented with protease and phosphatase inhibitors and DTT) and finally sonicated. The samples were denatured with Laemmli buffer $2 x$ added to each sample at a 1:1 ratio. All the protein extracts were boiled at $95^{\circ} \mathrm{C}$ for $5 \mathrm{~min}$ before use. A total of $30 \mu \mathrm{g}$ of protein was run on a $10 \%$ SDS-PAGE gel and transferred to a PVDF membrane. Then, it was incubated with a solution of 5\% non-fat milk in TBST for $1 \mathrm{~h}$ at room temperature. The primary antibodies against p-PKC pan $(1: 1,000)$, SOX2 (1:1,000), Oct-4A $(1: 1,000)$, and NANOG $(1: 1,000)$ were diluted in TBST with $1 \%$ non-fat milk supplemented with azide. After the incubation period, the immunocomplexes were detected with anti-rabbit antibody $(1: 1,000)$ and conjugated with horseradish peroxidase. Bands were obtained after exposing the membranes to X-ray film and analysed through densitometry scanning. The protein expression was quantified using ImageJ $1.49 \mathrm{v}$ software (Wayne Rasband) with the expression of $\beta$-actin used as a loading control. Each experiment was repeated three times.

Cell apoptosis analysis by flow cytometry. Cells were collected after $48 \mathrm{~h}$ of incubation with TMZ and/or TMX, washed with PBS, resuspended in binding buffer, and incubated with Annexin V (AV) (BD Biosciences) and propidium iodide (IP) (BioLegends) for $15 \mathrm{~min}$ in the dark as previously described (6). Cells were diluted in binding buffer and analysed using a FACSCalibur flow cytometer. The experiments were performed in triplicate, and the results were analysed through CellQuest ${ }^{\mathrm{TM}}$ and data analysed by modifit LTMM software.

Cell cycle analysis by flow cytometry. The cell cycle analysis was performed by flow cytometry, using the detection kit PI/RNAse (Immunostep), after the cells were incubated for $48 \mathrm{~h}$ with TMZ and/or TMX, as previously described (6). Briefly, after incubation, cells were collected and washed with PBS, and the pellet was resuspended in cold $70 \%$ ethanol, during vortex agitation, and finally incubated during $30 \mathrm{~min}$ on ice. Cells were incubated in in PI/RNAse solution. A total of 20,000 events were acquired, and cells were evaluated through CellQuest and data analysed by modifit LTMM software. The results are expressed by the percentage of cells in each phase 

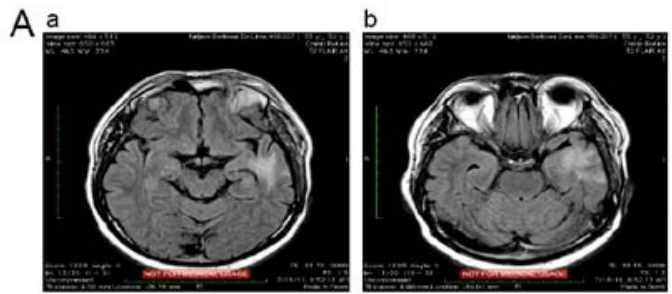

$B$

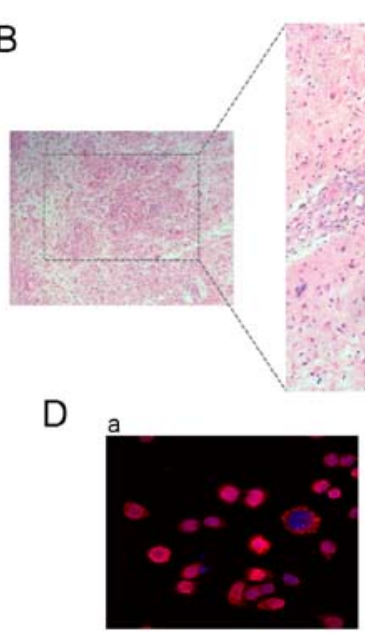

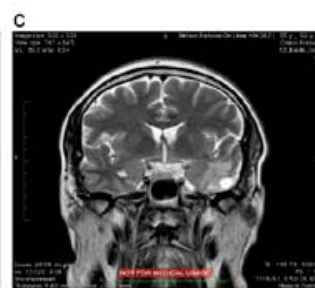

C
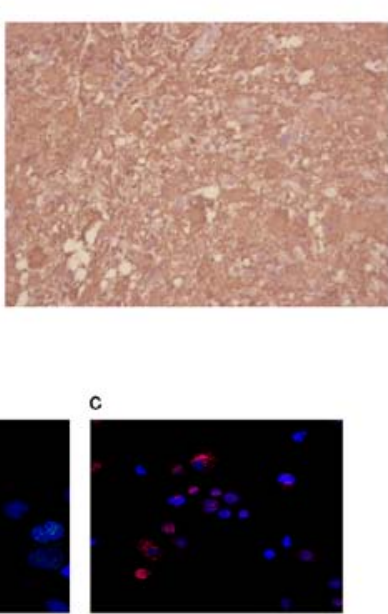
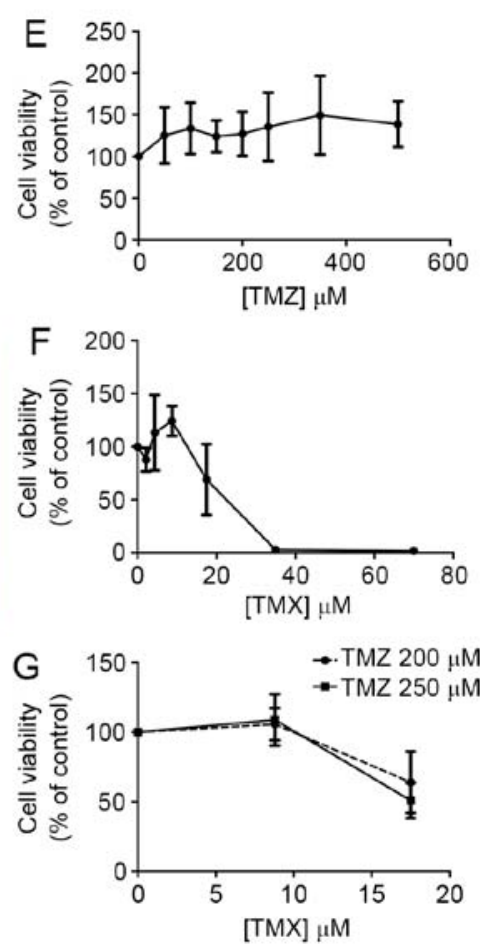

Figure 1. GBM cell line isolation and characterization and evaluation of the effect of the TMX and TMZ combination on cell viability. (A) Magnetic resonance image of the patient. (a and b) Axial FLAIR are two cuts in different slices, showing the infiltration of brain tissue adjacent to the lesion; (c) sequence termed T2 shows the lesion and the surrounding edema with a cyst in its interior, which represents a central necrosis. (B) Haematoxylin-eosin staining of GBM11 cells showing vascular endothelial proliferation, cellular pleomorphism, nuclear atypia and necrosis; left image x100, right image, $\mathrm{x} 400$ magnification. (C) GFAP-positive staining at the time of the diagnosis. (D) Positive stem-like cell markers expression: (a) SOX2, (b) OCT4 and (c) NANOG. The nuclei were counterstained with DAPI. (E) GBM11 cells were treated with TMZ $(0-350 \mu \mathrm{M})$ or $(\mathrm{F}) \mathrm{TMX}$ alone $(0-70 \mu \mathrm{M})$ and $(\mathrm{G})$ with the combination of two doses above the $\mathrm{IC}_{50}$ of each drug individually, e.g. 8.8 $\mu \mathrm{M} \mathrm{TMX}+200 \mu \mathrm{M}$ TMZ; $8.8 \mu \mathrm{M}$ TMX $+250 \mu \mathrm{M} \mathrm{TMZ} ; 17.5 \mu \mathrm{M} \mathrm{TMX}+200 \mu \mathrm{M}$ TMZ; $17.5 \mu \mathrm{M}$ TMX $+250 \mu \mathrm{M}$ TMZ. Dose-response curves represent the mean \pm SEM of 3 independent experiments for each concentration tested.

of cell cycle with a mean \pm SEM of at least three independent experiments. A total of 20,000 events were acquired, and cells were evaluated through CellQuest ${ }^{\mathrm{TM}}$ and were data analysed by modifit LTMM software.

Cell proliferation using EdU assay. Cells were plated in 6-well plates with different TMZ and/or TMX concentrations for $48 \mathrm{~h}$, and the effect on the proliferation rate was assayed using the EdU (5-ethynyl-2'-deoxyuridine) kit, exactly as previously described (6). In the final step, cells were incubated with anti-EdU-antibody working solution for $30 \mathrm{~min}$ at $37^{\circ} \mathrm{C}$ in a humidified atmosphere $\left(5 \% \mathrm{CO}_{2}\right)$. The incorporation of EdU was analysed by flow cytometry and data were analysed with modifit LTMM software.

Evaluation of cell migration ability. Cell migration was studied according to the method described by Liang et al (21). After the cells incubation with TMZ and/or TMX at different concentrations, for $48 \mathrm{~h}$, and the cell monolayer was scraped in a straight line with a p200 pipette tip, just as previously described (6). The debris were removed by washing the cells with culture medium and new culture medium was added. ImageJ software (National Institutes of Health) was used to record the coordinates for each scratch location using a computer-controlled stage. The mean scratch width at $6 \mathrm{~h}$ was compared to the original scratch width $(0 \mathrm{~h})$. Each experiment was repeated three times.
Statistical analysis. Statistical analysis was performed on GraphPad Prism 5 for Windows, version 5.00. After confirmation of the assumption of normality and homogeneity of variance across groups, the groups were compared by nested design with analysis of variance and post-hoc comparison, with correction of $\alpha$ error according to Bonferroni probabilities to compensate for multiple comparisons. All values were expressed as mean \pm SEM, $\mathrm{P}<0.05$.

\section{Results}

Establishment and characterization of GBM11 cell line. Surgical biopsy from a glial tumor diagnosed as a recurrent GBM was used in this study and U87 and U118 were a generous gift from another laboratory. The diagnosis was based on magnetic resonance imaging (MRI), which showed a typical ring-shaped appearance with a hypodense area due to necrosis, peripheral contrast enhancement, and edema that indicates a GBM (Fig. 1A). Haematoxylin and eosin (H\&E) staining revealed hypercellular injury with a fibrillary background and significant atypia, glomeruloid vessels, and extensive areas of necrosis (Fig. 1B). Also, immunohistochemistry analysis showed GFAP-positive cells (Fig. 1C) and negativity for cytokeratin pool (AE1/AE3), TTF-1, chromogranin, synaptophysin, CK7, CK20 and PSA (data not shown).

After tumor removal, cells were isolated and cultured as previously described for other GBM cultures established in our 
A
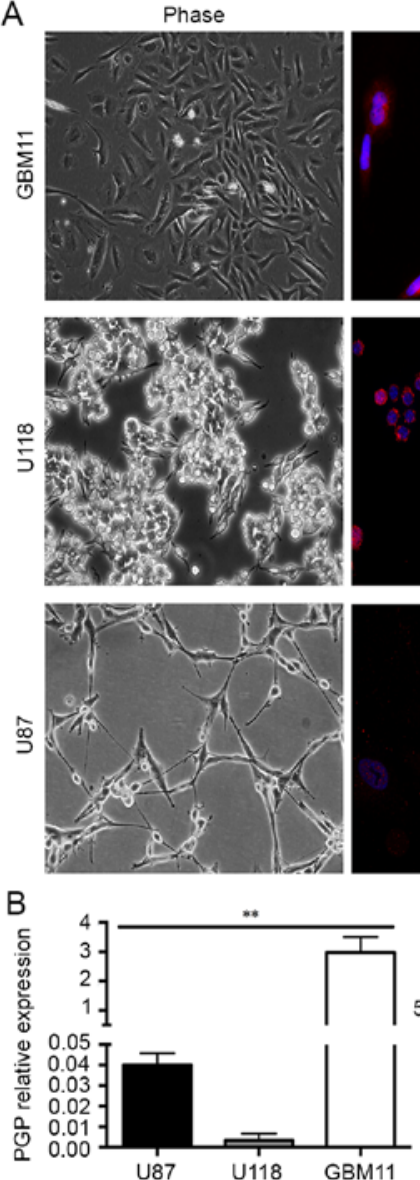

$\mathrm{D}$
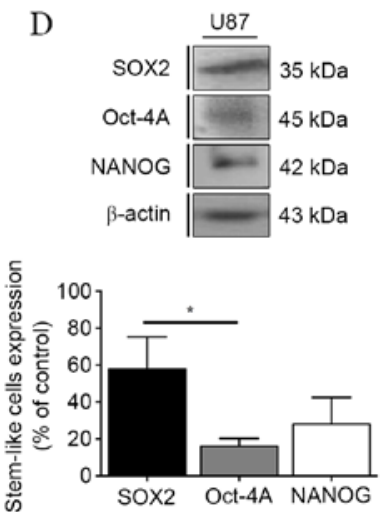

GFAPIDAPI
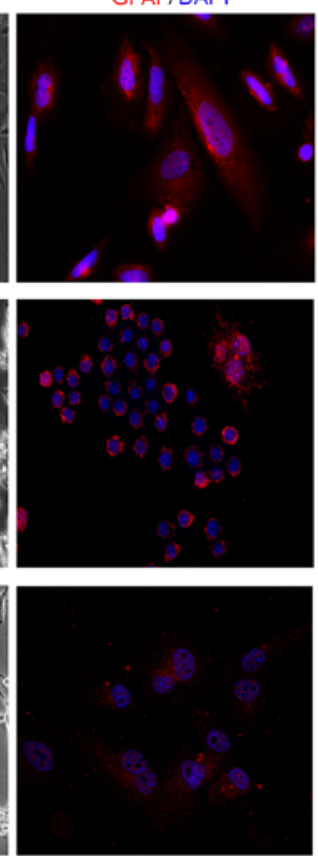

C

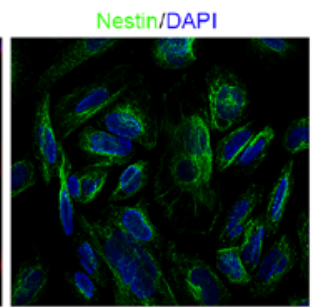

Phalloidin/DAPI
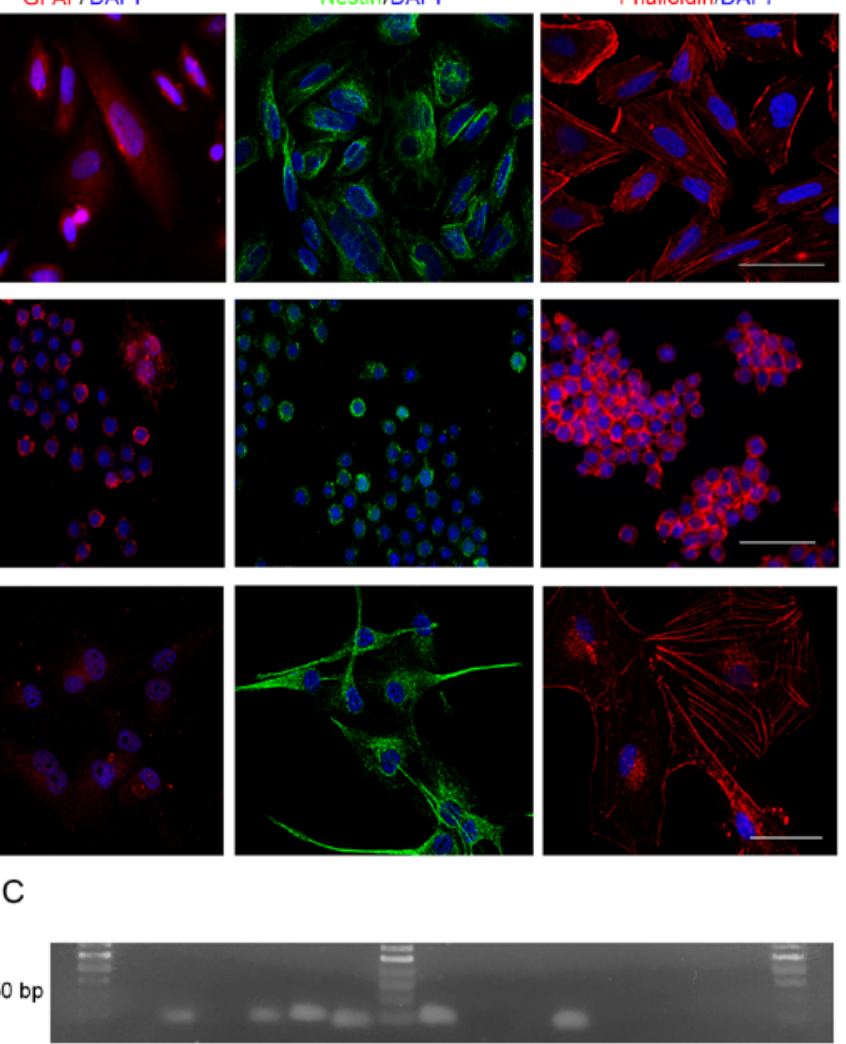

MM $\frac{U M}{G B M 11} \frac{U M}{U 87} \frac{U M}{U 118} \quad \frac{U M}{U C} \frac{U M}{M C} \frac{U M}{U N C} \frac{U M}{H_{2} \mathrm{O}}$ MM
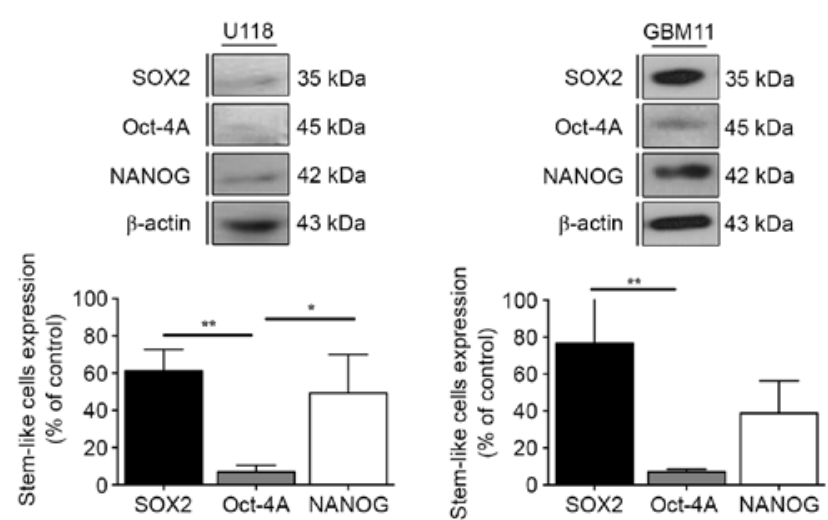

Figure 2. Evaluation of the resistance mechanisms in GBM cell lines. (A) Nestin, GFAP and phalloidin positive-staining were analysed for U87 and U118 cell lines. (B) PGP expression was quantified in the three GBM cell lines, U87, U118 and GBM11 by flow cytometric analysis in a BD FACSCalibur system. A total of 10,000 events were collected. Relative expression was obtained by PGP expression compared to the respective isotype and corresponds to the \% of gated cells. (C) MGMT methylation pattern was analysed through methylation-specific PCRs for U87, U118 and GBM11 cells lines. UC, universal unmethylated control (bisulfite converted); MC, universal methylated control (bisulfite converted); UNC, universal not converted unmethylated control (not bisulfite converted); MM, molecular marker of $50 \mathrm{bp}$. (D) The expression of SOX2, Oct-4A and Nanog in U87, U118 and GBM11 cell lines was quantified by western blot analysis. Statistical analysis was performed in GraphPad Prism 5 for Windows (version 5.00; GraphPad Software, Inc., San Diego, CA, USA). Each value represents the mean \pm SEM from three independent experiments, ${ }^{*} \mathrm{P}<0.05,{ }^{* *} \mathrm{P}<0.01$.

laboratory (16). The presence of stem-like cell markers, namely SOX2, OCT-4A and Nanog was also confirmed (Fig. 1D). We also evaluated the viability of GBM11 cells in the presence of TMX and TMZ, by MTT assay. Treatment with TMZ alone did not induce any alteration in cell viability (Fig. 1E), whereas treatment with TMX alone showed reduction of cell viability, with an $\mathrm{IC}_{50}$ of $25.6 \mu \mathrm{M}$ (Fig. $\left.1 \mathrm{~F}\right)$. On the other hand, the combination of TMX $(8.8 \mu \mathrm{M})+\mathrm{TMZ}(250 \mu \mathrm{M})$ induced a reduction of $49.2 \%$ in cell viability (Fig. 1G).
Resistance mechanisms evaluation of different GBM cell lines. The U87 and U118 cell lines, previously studied, and the new GBM11 cell line established in our laboratory revealed a positive staining for Nestin, a neuronal marker, and for GFAP, usually overexpressed in GBM cells, as well as a different F-actin organization by phalloidin staining (Fig. 2A), which suggests a similar origin of these three cell lines. Since the activity of P-glycoprotein (PGP) may prevent the accumulation of several chemotherapeutic drugs in glioma cells, we evaluated 
A

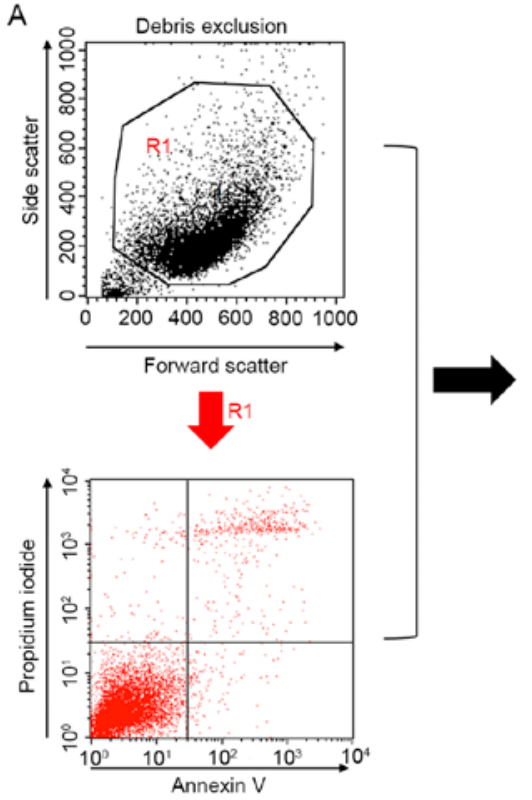

D
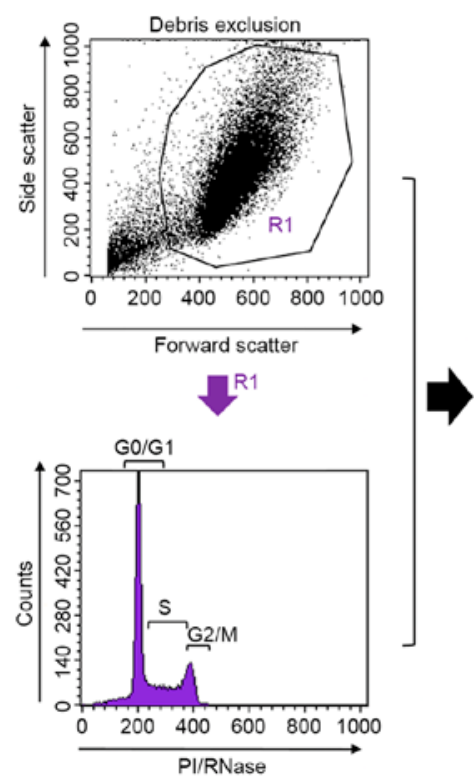

B

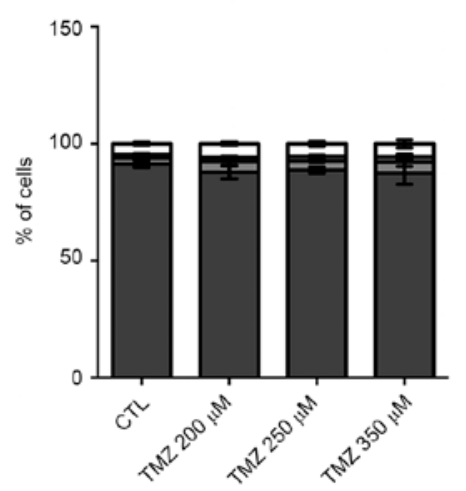

C

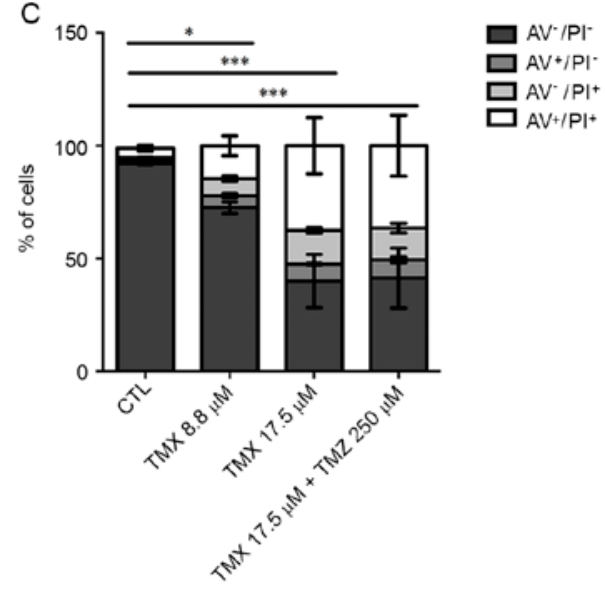

Figure 3. Effects of TMX and TMZ combination on cell death and cell cycle of GBM11 cells. Following the incubation of GBM11 cells with TMX and/or TMZ for $48 \mathrm{~h}$, cells were stained with Annexin V (AV) and propidium iodide (PI) and analysed by flow cytometry. (A) Debris was removed to obtain the viable cell region, R1. The R1 region was used to analyse AV and PI expression by flow cytometry. The analysis was based on the percentage of gated positive cells. (B) TMZ alone was added to GBM11 cells in different concentrations. (C) TMX and/or in combination with TMZ was added to GBM11 cells in different concentrations. The chosen doses were above the dose that inhibited growth by $50 \%\left(\mathrm{IC}_{50}\right)$, respectively. The $\mathrm{AV}$ positive cells, PI positive cells, $\mathrm{AV}$ and PI double-positive cells and the live cells (double-negative) were immediately analysed by flow cytometry in a BD FACSCalibur system and evaluated in the FL2 and FL1 channel, respectively. A total of 10,000 events were collected. (D) Cell cycle analysis was determined by gating G0/ G1, S and G2/ M on PI-area signal by flow cytometry after the debris were removed to obtain the $\mathrm{R} 1$ region. ${ }^{*} \mathrm{P}<0.05,{ }^{* * *} \mathrm{P}<0.01,{ }^{* * * *} \mathrm{P}<0.001$.

the expression of PGP in all GBM cell lines $(17,22,23)$. The results showed that in GBM11 the PGP expression was 3-fold higher compared with the GBM cells U87 and U118 (Fig. 2B).

It is also well known that methylation of the MGMT promoter can affect the sensitivity of cells to TMZ $(24,25)$. These findings led us to analyse the methylation status through a methylation-specific PCR in the three GBM cell lines. In U87 and GBM11 cell lines, the MGMT proved to be completely methylated and in the U118 cell line the MGMT showed partial methylation (Fig. 2C). Regarding the stem-like cell markers expression we noted that the U87 cell line present $61.3 \pm 11.5 \%$ of SOX $2 ; 6.8 \pm 3.7 \%$ of 

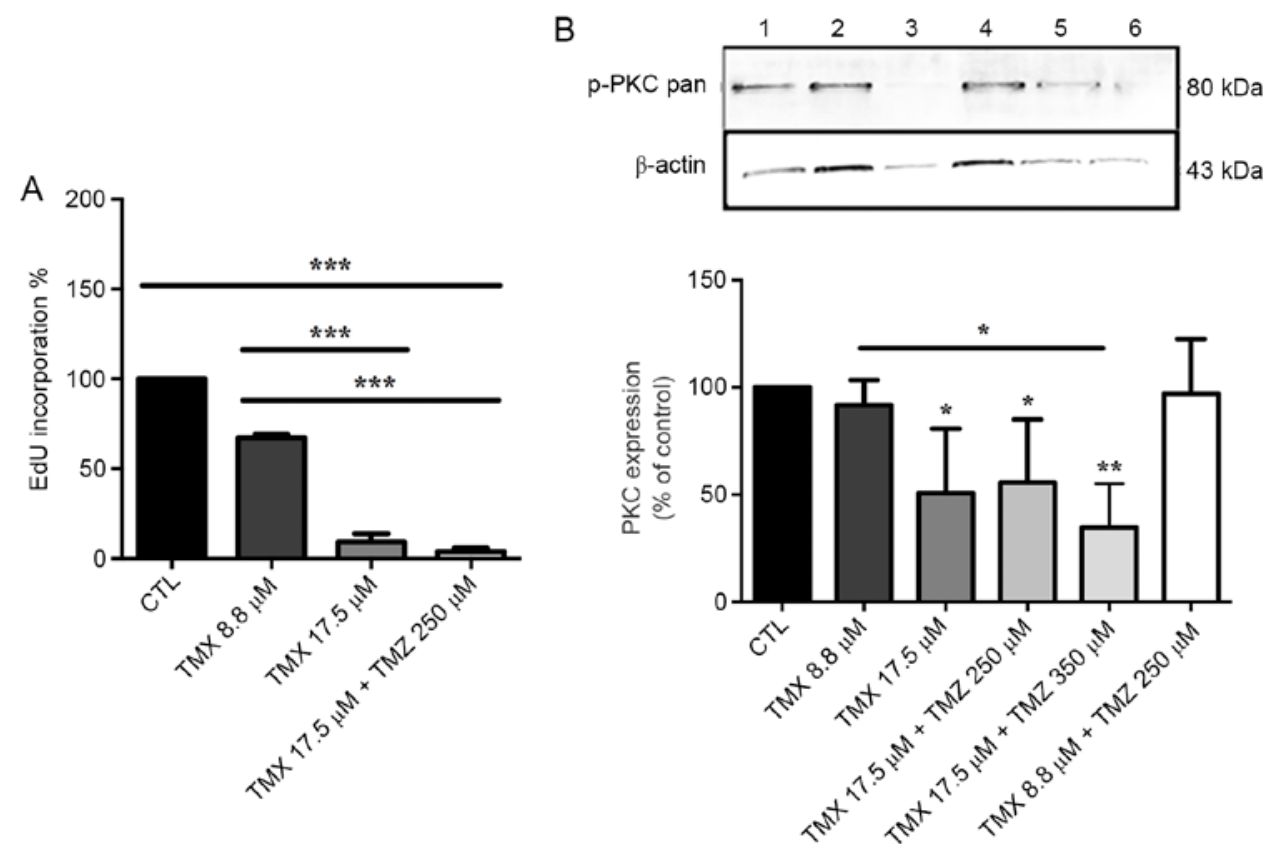

Figure 4. Effects of TMX and TMZ combination on EdU incorporation and p-PKC expression of GBM11 cells. (A) The proliferation rate was evaluated by measuring the incorporation of EdU. Analysis were performed with a BD FACSCalibur system evaluated in the FL2 and FL1 channel and a total of 10,000 events were collected. (B) The effect of TMX and/or TMZ on PKC-pan expression was evaluated by western blot analysis. Loading control was performed with an antibody for $\alpha$-tubulin. The bands numbered from 1 to 6 were in the same order that they appear in the graph. Each value represents the mean \pm SEM from three independent experiments, ${ }^{*} \mathrm{P}<0.05,{ }^{* * *} \mathrm{P}<0.01,{ }^{* * * *} \mathrm{P}<0.001$.

Oct- $4 \mathrm{~A}$; and $49.3 \pm 20.7 \%$ of NANOG. The U118 cell line present $57.9 \pm 17.3 \%$ of SOX $2 ; 16.01 \pm 4.2 \%$ of Oct $-4 \mathrm{~A}$; and $28.0 \pm 14.4 \%$ of NANOG. Furthermore, the GBM11 cell line present $76.8 \pm 25.8 \%$ of SOX2; $7.0 \pm 1.5 \%$ of Oct- $4 \mathrm{~A}$; and $38.8 \pm 17.4 \%$ of NANOG (Fig. 2D).

Evaluation of death and cell cycle in GBM11 cells treated with TMX and TMZ. To evaluate cell death with the combined therapy compared with monotherapy with TMZ, we stained the cells with Annexin V (AV), to analyse apoptotic cells, and with propidium iodide (PI), to analyse necrotic cells, by flow cytometry (Fig. 3A). TMZ alone did not induce cell death in GBM11 (Fig. 3B). However, $17.5 \mu \mathrm{M}$ of TMX induced an increase of $7.5 \pm 0.7 \%$ in apoptosis and $37.5 \pm 21.5 \%$ in late apoptosis, respectively, compared to control cells. Combined treatment with $17.5 \mu \mathrm{M} \mathrm{TMX}+250 \mu \mathrm{M}$ TMZ induced an increase of $8.1 \pm 2.3 \%$ in apoptosis and $36.5 \pm 23.4 \%$ in late apoptosis, $\mathrm{P}<0.001$ (Fig. 3C). Cell cycle analysis showed an arrest in the G1 phase when TMX was administered alone and in combination with TMZ, $\mathrm{P}<0.001$ (Fig. 3D).

Evaluation of EdU incorporation and p-PKC-pan regulation in GBM11 cells treated with TMX and TMZ. EdU incorporation in $17.5 \mu \mathrm{M}$ of TMX and in $17.5 \mu \mathrm{M} \mathrm{TMX}+250 \mu \mathrm{M}$ TMZ was reduced by $90.7 \pm 8.0$ and $96.2 \pm 3.4 \%$, respectively, compared to control cells, $\mathrm{P}<0.001$ (Fig. 4A).

We verified that GBM11 cells also express p-PKC-pan. The $17.5 \mu \mathrm{M}$ of TMX induced a significant reduction of $49.3 \pm 30.1 \%$ in p-PKC-pan regulation, $\mathrm{P}<0.05$. When combined with TMZ, the reduction of p-PKC-pan was $44.3 \pm 29.4 \%$ with $17.5 \mu \mathrm{M}$ $\mathrm{TMX}+250 \mu \mathrm{M}$ TMZ $(\mathrm{P}<0.01)$ and $65.2 \pm 20.3 \%$ with $17.5 \mu \mathrm{M}$ TMX + $350 \mu \mathrm{M}$ TMZ (Fig. 4B).
Study of cell migration and organization of F-actin filaments in GBM11 cells treated with TMX and TMZ. To evaluate the effect of TMX and TMZ co-treatment on GBM11 cells, we performed the scratch assay. After $6 \mathrm{~h}$, control cells moved and filled the scratch (Fig. 5A). When cells were incubated with $17.5 \mu \mathrm{M}$ TMX or with TMX $17.5 \mu \mathrm{M}+250 \mu \mathrm{M}$ TMZ, cell motility was reduced by $80.8 \pm 29.1$ and $73.9 \pm 13.9 \%$ compared to control cells, respectively, $\mathrm{P}<0.05$ (Fig. 5B). Phalloidin staining was performed to evaluate the cytoskeleton organization in the presence of TMX and/or TMZ (Fig. 5C).

\section{Discussion}

Despite the lack of a successful response, temozolomide (TMZ) is still considered the gold-standard for GBM treatment. Currently, alternative treatment options for patients with TMZ resistant GBMs are desperately needed (26). Tamoxifen (TMX) is an estrogen receptor (ER) modulator commonly used for the treatment of ER-positive breast cancer recently considered to have many other antitumor actions, mainly in the phosphorylated protein kinase $\mathrm{C}(\mathrm{PKC})$ regulation when used in higher concentrations $(10,25-27)$. Phosphorylated PKC is one of the most enigmatic signaling pathways that may promote or inhibit apoptosis and cell survival, as previously described (6). TMX is well known to be one of p-PKC inhibitors used in in vitro studies with glioma cells and also in clinical trials with GBM patients. Besides the in vivo studies were disappointing since treatment of patients with recurrent malignant glioma with low doses of TMX did not significantly increase the survival rate of the patients, the clinical trials using high doses of TMX alone or in combination with other cytotoxic agents, have yielded 

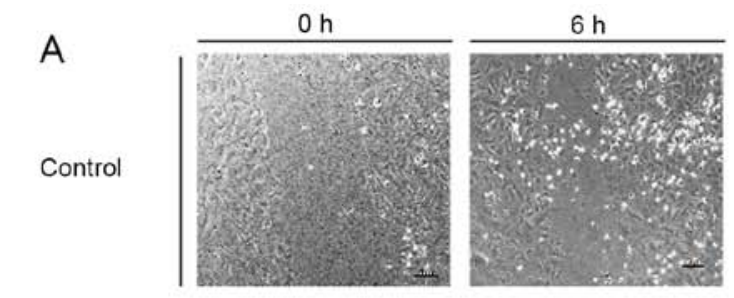

B
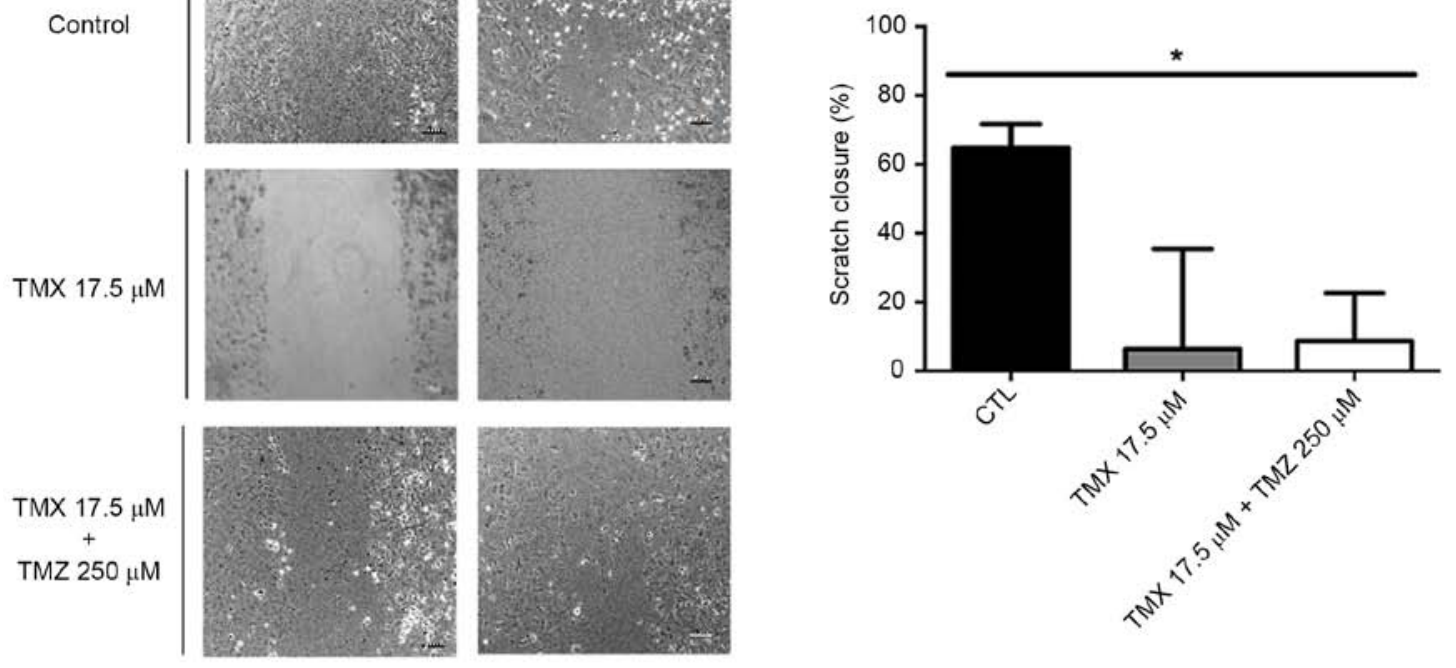

C
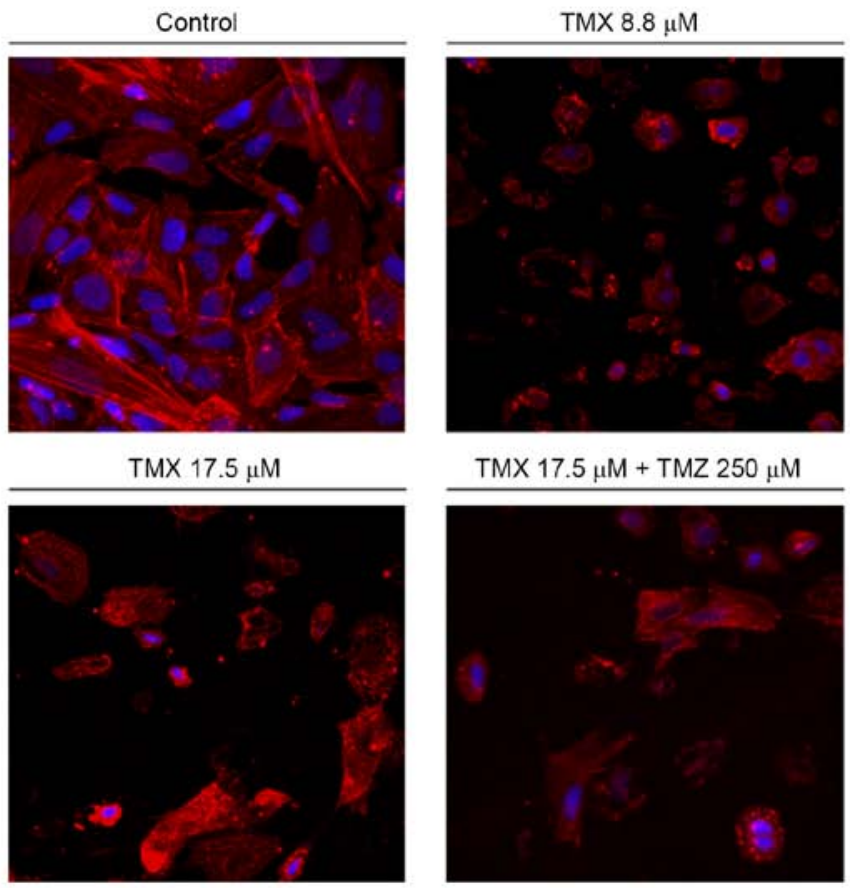

Figure 5. Effects of TMX and TMZ combination on cell migration capability and F-actin filament organization of GBM11 cells. (A) The images are of GBM11 cells from the scratch assay. The scratch closure was measured at two time-points (T0 and T6) after the scratch was made in the culture dish. Every image was acquired at the same magnification of x10 (x10/0.25 Ph1 N-Plan) (scale bar, $100 \mu \mathrm{m}$ ) with a DMI3000B light microscope (Leica Microsystems, Heerbrugg, Switzerland) and acquired with Leica Application Suite v 4.3. ImageJ software was used to record the coordinates for each scratch location. (B) Statistical analysis was performed in GraphPad Prism 5. Each value represents the mean \pm SEM from three independent experiments, "P $<0.05$. (C) Cells were fixed and F-actin was stained with Alexa Fluor 555 phalloidin. Nuclei were counterstained with DAPI. Observations were made with a Zeiss LSM 510 meta confocal microscope at a magnification of $x 40$, using a filter set with an excitation filter of $568 \mathrm{~nm}$ and a barrier filter of $585 \mathrm{~nm}$. Red indicates F-actin staining and blue indicates the nuclei. All the doses chosen were above the one that inhibited growth by $50 \%\left(\mathrm{IC}_{50}\right)$, respectively.

better results $(6,28-31)$. We recently described the success of TMX and TMZ combination in two GBM cell lines, U87 and U118. In order to study the heterogeneity between GBM cells and the variability in the chemotherapeutic response, similarly to that observed in GBM patients, we stablished the new GBM cell line GBM11 and compared the mechanisms underlying chemoresistance and the response to treatment with the two cell lines previously studied, the U87 and U118 (6).
A tumor sample from GBM was analysed histologically by the Pathology Service of the Federal University of Rio de Janeiro Hospital, as described by Faria et al (16). Prior to isolation of the GBM cells and at the time of the diagnosis, the tumor was classified as GBM due to the: i) magnetic resonance diagnosis (Fig. 1A); ii) histopathological characteristics of GBM by staining with H\&E in paraffin sections (Fig. 1B); iii) the positive GFAP immunostaining, which is currently 
used for diagnosis of GBM (Fig. 1C) (32); and iv) existence of a previous GBM lesion. Subsequently, the tumor cells from the biopsy sample of GBM were isolated and established in culture. GBM is also characterized as a heterogeneous tumor that has a subpopulation of glioma stem-like cells (GSCs), known to be chemo- and radioresistant, properties that are responsible for tumor recurrence (33-35). In fact, our GBM cells also expressed stem-like cell markers, mainly SOX2, OCT-4A and Nanog (Fig. 1D), probably because these tumor stem-like cells have been selected through the previous TMZ treatment. GBM11 cells could also grow in an in vivo animal model (data not shown), as described by Garcia et al (36). This suggests that the glioma stem-like cells are able to contribute to the tumor growing in vivo and that the previous treatment with TMZ may have contributed to the recurrence of a tumor endowed with a higher number of cancer stem-like cells.

Regarding cell cytotoxicity, we noted an expected resistance of GBM11 to TMZ treatment (6) (Fig. 1E), similarly to that observed in the U87 and U118 cell lines, which was in accordance with the low survival rate of GBM patients treated with TMZ $(2,7,8,15)$. Regarding cell cytotoxicity of TMX in GBM11 cells we observed a higher $\mathrm{IC}_{50}, 25.6 \mu \mathrm{M}$, compared, respectively, to 9.1 and $7.3 \mu \mathrm{M}$ from U87 and U118, previously published (Fig. $1 \mathrm{~F}$ ), which suggests that this new cell line presents a more resistant behavior when compared to U87 and U118. The combined treatment of GBM11 with TMX and TMZ induce a decrease in cell viability until $49.2 \%$ using doses below the $\mathrm{IC}_{50}$ of each drug alone. Similar cytotoxicity was observed in U87 cells, $~ 50.0 \%$ in cell viability decrease and a higher one observed in U118 of $90.0 \%$ (Fig. 1G). These results are in accordance with the higher resistance of GBM11 cells and higher sensitivity of U118 to TMX alone.

After the analysis of the GFAP and Nestin positive expression and F-actin filament staining, confirming a GBM phenotype of all three GBM cells (Fig. 2A), we analysed the expression of PGP. PGP is expressed by endothelial cells in the brain and in the newly formed blood vessels in glioma. PGP recognizes structurally unrelated chemotherapeutic agents such as vincristine, etoposide, doxorubicin, taxol and temozolomide $(18,37-40)$. In the present study we observed that the PGP expression in GBM11 is significantly higher than compared to U87 and U118. It suggests that PGP expression is enhanced by previous TMZ treatment and may explain the more aggressive phenotype of recurrent gliomas. Thus, we considered that, together with the higher $\mathrm{IC}_{50}$ of TMX and lower cell viability of TMX plus TMZ treatment, GBM11 could be used to evaluate the chemoresistance of different therapeutic agents in future studies (Fig. 2B).

Regarding the mechanisms of chemoresistance of GBM to TMZ, we evaluated the expression of O6-methylguanine-DNA methyltransferase $(M G M T)(24,41)$. Accordingly, analysis of the methylation pattern revealed a total methylation of the MGMT in GBM11 and U87 cell lines and a partial methylation in U118 cell line, suggesting that the resistance of TMZ is probably not related with the $M G M T$ action. In the U118 case, due to a partial methylation pattern of the $M G M T$ we could expect a higher resistance to TMZ compared with the other cell lines (Fig. 2C). Still, MGMT alone is not always correlated with resistance to TMZ in GBM, which was apparently the case of these three cell lines $(37,40,41)$. Accordingly, since the glioma stem-like cells are known to be chemo- and radioresistant and so responsible for tumor recurrence (42-45), the stem-like cell marker expression evaluation confirmed that the GBM11 could be the more resistant cell line since it presents higher levels of SOX2, the overexpression of which has been correlated with poor prognosis in gliomas, compared to U87 and U118 cell lines (Fig. 2D). In fact SOX2 levels must be tightly controlled for proper development of the nervous system. Specifically, deregulation of SOX2 levels in chick neural stem cells (NSC) has been shown to disrupt their fate (46).

Similarly to the results obtained for the U87 and U118 cell lines, we observed an induction of cell death (Fig. 3A-C) and an induction of cell cycle arrest (Fig. 3D) in GBM11 cells treated with TMX and TMZ, although the TMX alone treatment induce a similar effect than the combined therapy in this cell line. It may suggest that for recurrent tumors previously treated with TMZ accordingly to Stupp protocol, the best choice of second-line treatment may be only TMX to reduce putative side effects of combined treatment with TMZ. Also, a reduction in cell proliferation (Fig. 4A) was observed in GBM11 cells, probably due to the decreased expression of p-PKC-pan (Fig. 4B).

We finally observed a reduction of cell migration (Fig. 5A and B), which could be explained, not exclusively, but consistently, by the visible disorganization of F-actin filaments (Fig. 5C).

Altogether, when treated with TMX, our new GBM11 cell line presented a higher $\mathrm{IC}_{50}$ of TMX alone, higher reduction of cell proliferation, probably due to the reduction of p-PKC expression, and cell migration capability and a higher expression of PGP compared to U87 and U118 cell lines previously described (Table I). The increase of PGP expression has been correlated with a poor response to therapy, which may justify the higher resistance of GBM11 cells $(37,39,41,47)$. Also, TMX is known to inhibit drug transport since it interacts with PGP inhibiting PGP-dependent drug transport (47). They may be more resistance also due to the previous treatment with TMZ, but the overexpression of PGP and the higher amount of stem-like cells are more likely to be responsible for the GBM11 resistant profile. In this way, the concentration of TMX required to induce an effect would be expected to be higher compared to U87 and U118 cell lines, which is also in accordance with our results.

However, and probably due to the higher resistance of this new GBM cell line, the combination of TMX and TMZ did not have a synergistic effect as observed in U87 and U118 cell lines. In GBM11 the results between combined or monotherapy are the same, which could represent action in another receptor site of interaction and would be an alternative chemotherapeutic approach for GBM. Besides TMX can actually be very important on p-PKC regulation, and consequently, interfere with proliferation, survival and migration of glioma cells, the contribution of chemotherapeutic drugs depends on the GBM cell characteristics. In the present study, we evaluated the effect of TMX on TMZ-resistant GBM cell lines, which express different levels of PGP expression and similar MGMT activity. The $M G M T$ is totally methylated in the GBM11 and U87 cell lines, which justifies the 
chemoresistance of these cells to TMZ. However, in the U118 cell line we could see only a partial methylation of MGMT, which could explain some of the TMZ resistance behavior but a better response of the combined therapy, since TMX could sensitize cells to TMZ action in this cell line, which is in accordance with our results (Table I). We found that TMX alone significantly inhibited the viability of TMZ-resistant GBM cells with higher expression of PGP, and induced apoptosis of glioma cells in vitro. In GBM11 we observed no need for TMZ addition in the chemotherapeutic approach, besides this drug combination with TMX presented a huge advantage in U87 and U118 cells. This response suggests that TMX alone can be used as a second-line therapy in patients bearing recurrent tumors previously treated with TMZ, instead of a combination of TMZ and TMX (48). It also emphasizes the heterogeneity response between GBM cells, which reflects the same variability between different GBM, highlighting the urgent need of the establishment of a personalized therapy $(6,14,15)$.

Our results propose TMX alone treatment as a successful approach in GBM cells that have previously been treated according to the Stupp protocol (12). Since the TMX and TMZ constitutes a beneficial combination for U87 and U118 cells, and since TMZ is still part of the gold-standard for GBM treatment, the combination constitutes a therapeutic approach that still reaches a wide range of GBM cells, especially those that still have not been exposed to TMZ. Furthermore, these results open new avenues to recognize different cell responses according to tumor heterogeneity that together might evidence functional differences between gliomas entities.

\section{Acknowledgements}

The present study was financed by FEDER funds through the Operational Programme Factors CompetitivenessCOMPETE and National Funds through FCT-Foundation for Science and Technology under the project 'National funds from FCT' of the Fundação para a Ciência e Tecnologia, under a Ph.D. fellowship to Joana Balça Pinheiro da Costa e Silva (SFRH/BD/51993/2012); and by the project PEst-C/ SAU/LA0001/2013-2014. Additional funding was granted by FEDER/COMPETE/ FCT PTDC/EBB-EBI/120634/2010 and PDTC/QUI-BIQ/120652/2010 and QREN: CENTRO01-0762-FEDER-00204. This study was also supported by the Conselho Nacional de Desenvolvimento Científico e Tecnológico (CNPq), Fundação Carlos Chagas Filho de Amparo à Pesquisa do Estado do Rio de Janeiro (FAPERJ), and Instituto Estadual do Cérebro Paulo Niemeyer (IECPN) and Pró-Saúde Associação Beneficente de Assistência Social e Hospitalar, Rio de Janeiro, Brazil.

\section{References}

1. Louis DN, Perry A, Reifenberger G, von Deimling A, Figarella-Branger D, Cavenee WK, Ohgaki H, Wiestler OD, Kleihues P and Ellison DW: The 2016 World Health Organization Classification of Tumors of the Central Nervous System: A summary. Acta Neuropathol 131: 803-820, 2016.

2. Stupp R, Hegi ME, Gilbert MR and Chakravarti A: Chemoradiotherapy in malignant glioma: Standard of care and future directions. J Clin Oncol 25: 4127-4136, 2007. 
3. Stupp R, Mason WP, van den Bent MJ, Weller M, Fisher B, Taphoorn MJ, Belanger K, Brandes AA, Marosi C, Bogdahn U, et al; European Organisation for Research and Treatment of Cancer Brain Tumor and Radiotherapy Groups; National Cancer Institute of Canada Clinical Trials Group: Radiotherapy plus concomitant and adjuvant temozolomide for glioblastoma. $\mathrm{N}$ Engl J Med 352: 987-996, 2005.

4. Lima FRS, Kahn SA, Soletti RC, Biasoli D, Alves T, da Fonseca AC, Garcia C, Romão L, Brito J, Holanda-Afonso R, et al: Glioblastoma: Therapeutic challenges, what lies ahead. Biochim Biophys Acta 1826: 338-349, 2012.

5. Huse JT, Holland E and DeAngelis LM: Glioblastoma: Molecular analysis and clinical implications. Annu Rev Med 64: 59-70, 2013.

6. Balça-Silva J, Matias D, do Carmo A, Girão H, Moura-Neto V, Sarmento-Ribeiro AB and Lopes MC: Tamoxifen in combination with temozolomide induce a synergistic inhibition of PKC-pan in GBM cell lines. Biochim Biophys Acta 1850: 722-732, 2015.

7. Carmo A, Carvalheiro H, Crespo I, Nunes I and Lopes MC: Effect of temozolomide on the U-118 glioma cell line. Oncol Lett 2: 1165-1170, 2011.

8. do Carmo A, Patricio I, Cruz MT, Carvalheiro H, Oliveira CR and Lopes MC: CXCL12/CXCR4 promotes motility and proliferation of glioma cells. Cancer Biol Ther 9: 56-65, 2010.

9. Hattermann $\mathrm{K}$ and Mentlein R: An infernal trio: The chemokine CXCL12 and its receptors CXCR4 and CXCR7 in tumor biology. Ann Anat 195: 103-110, 2013.

10. Zhou J, Atsina KB, Himes BT, Strohbehn GW and Saltzman WM Novel delivery strategies for glioblastoma. Cancer J 18: 89-99, 2012.

11. Safa AR, Saadatzadeh MR, Cohen-Gadol AA, Pollok KE and Bijangi-Vishehsaraei K: Glioblastoma stem cells (GSCs) epigenetic plasticity and interconversion between differentiated non-GSCs and GSCs. Genes Dis 2: 152-163, 2015.

12. Stupp R, Hegi ME, Mason WP, van den Bent MJ, Taphoorn MJ, Janzer RC, Ludwin SK, Allgeier A, Fisher B, Belanger K, et al; European Organisation for Research and Treatment of Cancer Brain Tumour and Radiation Oncology Groups; National Cancer Institute of Canada Clinical Trials Group: Effects of radiotherapy with concomitant and adjuvant temozolomide versus radiotherapy alone on survival in glioblastoma in a randomised phase III study: 5-year analysis of the EORTC-NCIC trial. Lancet Oncol 10: 459-466, 2009.

13. Thirant C, Bessette B, Varlet P, Puget S, Cadusseau J, Tavares SR, Studler JM, Silvestre DC, Susini A, Villa C, et al: Clinical relevance of tumor cells with stem-like properties in pediatric brain tumors. PLoS One 6: e16375, 2011.

14. Bogush T, Dudko E, Bogush E, Polotsky B, Tjulandin S and Davydov M: Tamoxifen non-estrogen receptor mediated molecular targets. Oncol Rev 6: e15, 2012.

15. Kahn SA, Biasoli D, Garcia C, Geraldo LH, Pontes B, Sobrinho M, Frauches AC, Romão L, Soletti RC, Assunção FS, et al: Equinatoxin II potentiates temozolomide- and etoposideinduced glioblastoma cell death. Curr Top Med Chem 12: 2082-2093, 2012.

16. Faria J, Romão L, Martins S, Alves T, Mendes FA, de Faria GP, Hollanda R, Takiya C, Chimelli L, Morandi V, et al: Interactive properties of human glioblastoma cells with brain neurons in culture and neuronal modulation of glial laminin organization. Differentiation 74: 562-572, 2006.

17. Linn SC, Giaccone G, van Diest PJ, Blokhuis WM, van der Valk P van Kalken CK, Kuiper CM, Pinedo HM and Baak JP: Prognostic relevance of P-glycoprotein expression in breast cancer. Ann Oncol 6: 679-685, 1995

18. Calatozzolo C, Gelati M, Ciusani E, Sciacca FL, Pollo B, Cajola L, Marras C, Silvani A, Vitellaro-Zuccarello L, Croci D, et al: Expression of drug resistance proteins Pgp, MRP1, MRP3, MRP5 and GST- $\pi$ in human glioma. J Neurooncol 74: 113-121, 2005.

19. Gonçalves AC, Cortesão E, Oliveiros B, Alves V, Espadana AI, Rito L, Magalhães E,Lobão MJ, Pereira A, Nascimento Costa JM, et al: Oxidative stress and mitochondrial dysfunction play a role in myelodysplastic syndrome development, diagnosis, and prognosis: A pilot study. Free Radic Res 49: 1081-1094, 2015.

20. Towbin H, Staehelin T and Gordon J: Immunoblotting in the clinical laboratory. J Clin Chem Clin Biochem 27: 495-501, 1989

21. Liang CC, Park AY and Guan JL: In vitro scratch assay: A convenient and inexpensive method for analysis of cell migration in vitro. Nat Protoc 2: 329-333, 2007.
22. Rittierodt M and Harada K: Repetitive doxorubicin treatment of glioblastoma enhances the PGP expression - a special role for endothelial cells. Exp Toxicol Pathol 55: 39-44, 2003.

23. Borowski E, Bontemps-Gracz MM and Piwkowska A: Strategies for overcoming $\mathrm{ABC}$-transporters-mediated multidrug resistance (MDR) of tumor cells. Acta Biochim Pol 52: 609-627, 2005.

24. Qiu ZK, Shen D, Chen YS, Yang QY, Guo CC, Feng BH and Chen ZP: Enhanced MGMT expression contributes to temozolomide resistance in glioma stem-like cells. Chin J Cancer 33: 115-122, 2014.

25. Hegi ME, Diserens A-C, Gorlia T, Hamou MF, de Tribolet N, Weller M, Kros JM, Hainfellner JA, Mason W, Mariani L, et al: MGMT gene silencing and benefit from temozolomide in glioblastoma. N Engl J Med 352: 997-1003, 2005.

26. He W, Liu R, Yang SH and Yuan F: Chemotherapeutic effect of tamoxifen on temozolomide-resistant gliomas. Anticancer Drugs 26: 293-300, 2015.

27. Couldwell WT, Hinton DR, He S, Chen TC, Sebat I, Weiss MH and Law RE: Protein kinase $C$ inhibitors induce apoptosis in human malignant glioma cell lines. FEBS Lett 345: 43-46, 1994.

28. Zhang W, Couldwell WT, Song H, Takano T, Lin JH and Nedergaard M: Tamoxifen-induced enhancement of calcium signaling in glioma and MCF-7 breast cancer cells. Cancer Res 60: 5395-5400, 2000.

29. O'Brian CA, Liskamp RM, Solomon DH and Weinstein IB: Inhibition of protein kinase $\mathrm{C}$ by tamoxifen. Cancer Res 45: 2462-2465, 1985

30. Kamburoğlu G, Kiratli H, Söylemezoğlu F and Bilgiç S: Clinicopathological parameters and expression of P-glycoprotein and MRP-1 in retinoblastoma. Ophthalmic Res 39: 191-197, 2007.

31. Hui AM, Zhang W, Chen W, Xi D, Purow B, Friedman GC and Fine HA: Agents with selective estrogen receptor (ER) modulator activity induce apoptosis in vitro and in vivo in ER-negative glioma cells. Cancer Res 64: 9115-9123, 2004.

32. Deck JH, Eng LF, Bigbee J and Woodcock SM: The role of glial fibrillary acidic protein in the diagnosis of central nervous system tumors. Acta Neuropathol 42: 183-190, 1978.

33. Altaner $\mathrm{C}$ and Altanerova V: Stem cell based glioblastoma gene therapy. Neoplasma 59: 756-760, 2012.

34. Jackson M, Hassiotou F and Nowak A: Glioblastoma stem-like cells: At the root of tumor recurrence and a therapeutic target. Carcinogenesis 36: 177-185, 2015.

35. Meacham CE and Morrison SJ: Tumour heterogeneity and cancer cell plasticity. Nature 501: 328-337, 2013.

36. Garcia C, Dubois LG, Xavier AL, Geraldo LH, da Fonseca AC Correia AH, Meirelles F, Ventura G, Romão L, Canedo NH, et al: The orthotopic xenotransplant of human glioblastoma successfully recapitulates glioblastoma-microenvironment interactions in a non-immunosuppressed mouse model. BMC Cancer 14: 923, 2014.

37. Tóth K, Vaughan MM, Peress NS, Slocum HK and Rustum YM: MDR1 P-glycoprotein is expressed by endothelial cells of newly formed capillaries in human gliomas but is not expressed in the neovasculature of other primary tumors. Am J Pathol 149: 853-858, 1996.

38. Sun H, Dai H, Shaik N and Elmquist WF: Drug efflux transporters in the CNS. Adv Drug Deliv Rev 55: 83-105, 2003.

39. Cordon-Cardo C, O'Brien JP, Casals D, Rittman-Grauer L, Biedler JL, Melamed MR and Bertino JR: Multidrug-resistance gene (P-glycoprotein) is expressed by endothelial cells at blood-brain barrier sites. Proc Natl Acad Sci USA 86: 695-698, 1989.

40. Schaich M, Kestel L, Pfirrmann M, Robel K, Illmer T, Kramer M, Dill C, Ehninger G, Schackert G and Krex D: A MDRl (ABCBI) gene single nucleotide polymorphism predicts outcome of temozolomide treatment in glioblastoma patients. Ann Oncol 20: 175-181, 2009.

41. Tomaszowski KH, Schirrmacher R and Kaina B: Multidrug efflux pumps attenuate the effect of MGMT inhibitors. Mol Pharm 12: 3924-3934, 2015.

42. Singh SK, Hawkins C, Clarke ID, Squire JA, Bayani J, Hide T, Henkelman RM, Cusimano MD and Dirks PB: Identification of human brain tumour initiating cells. Nature 432: 396-401, 2004.

43. Diaz A and Leon K: Therapeutic approaches to target cancer stem cells. Cancers (Basel) 3: 3331-3352, 2011.

44. Ortensi B, Setti M, Osti D and Pelicci G: Cancer stem cell contribution to glioblastoma invasiveness. Stem Cell Res Ther 4: 18, 2013. 
45. Seymour T, Nowak A and Kakulas F: Targeting aggressive cancer stem cells in glioblastoma. Front Oncol 5: 159, 2015.

46. Cox JL, Wilder PJ, Desler M and Rizzino A: Elevating SOX2 levels deleteriously affects the growth of medulloblastoma and glioblastoma cells. PLoS One 7: e44087, 2012.

47. Callaghan $\mathrm{R}$ and Higgins $\mathrm{C}$ : Interaction of tamoxifen with the multidrug resistance P-glycoprotein. Br J Cancer 71: 294-299, 1995.
48. Di Cristofori A, Carrabba G, Lanfranchi G, Menghetti C, Rampini P and Caroli M: Continuous tamoxifen and dose-dense temozolomide in recurrent glioblastoma. Anticancer Res 33: 3383-3389, 2013 